said, we take the difference between 28 and $15=13$, and multiply this difference by 0.36 , the product being 4.68. This quantity subtracted from $i 1$, gives 66.32 . The difference between 100 and $i 6.8$ being 23.2 , this quantity is added to 66.32 , and the sum, 89.52 , is the quantity of pure sugar in the sugar tested.

It has been suggested that the evaporation of methylic alcohol during the manipulations that have been described, must interfere with the accuracy of the resnlts obtained, but this does not seem to be the case. It might be possible to avoid evaporation entirely by leaving out the operation of grinding the mixture of sugar and methylic alcohol in a mortar, but, in this case, the results obtained would be less accurate on account of the impurities left in the sugar. Beyond avoiding working in a draft, no preeaution has been taken to prevent evaloration. One reason why the evaporation of the alcohol seems to have so little effect on the result, is that the operations of grinding and filtering occupy only a few minutes, during which no appreciable loss takes place.

\title{
XXII.-CONtribltions From the Laboratory of the Stevens Institute of TeChNology.
}

BY ALBERT R. LEEDS.

\section{I. - SOLUBILITY OF OZONE IN WATER.}

SChoENheis, in his numerous papers, taught that ozone is insoluble in water, and this statement was thence transferred to the accounts given of the properties of ozone by uther writers, and finally adopted is a universally admitted fact in chemical text-books.*

WiLLIA the solubility of ozone and, it should be added, with reference to ozone itself. He ascribed the peculiar properties belonging to the the oxygen set free by electrolysis, to the admixture of a peroxide ur acid of hydrogen. This body, according to Williamson, even when formed by the electrolysis of oxide of copper dissolved in sulphuric acid (in order that no hydrogen might be liberated at the same time), and after careful drying by calcium chloride, yielded when passed

* On Schoenbein's Ozone :" Faraday, Proe. Royal Inst., vol. i, p. $94 . \quad$ Elements of Chemistry : Miller, 1860, vol. ii, p. 23.

†"Some Experiments upon Ozone:" Phil. Mag., xxvii, p. 372. Chem. Soc. Mem., ii, p. 395. Liebig's Ann., liv, p. 127. 
over heated copper, a notable amount of water. In his final experiments, the copper was reduced by carbonic oxide rather than hydrogen, which was at first employed, for fear that in the latter case, the copper might retain occluded hydrogen.* This kind of ozone communicated to water through which it was passed, the characteristic odor and the property of decomposing potassium iodide. But the ozoniferous air, prepared by driving moist air through a tube filled with pieces of phosphorus, did neither. In another experiment, shen the air after passing over the phosphorus entered directly into a solution of iodide and starch, decomposition took place. Finally, a long and wide tube was filled with pieces of phosphorus, which were placed alternately. By heating the tube thus filled, the phosphorus was partly melted into the asbestos and partly sublimed upon it; thus exposing a far greater surface than in the former experiments. After complete cooling, atmospheric air was driven through the tube into the iodide and starch, but not the slightest reaction was produced. These different reactions are explained by Williamson, on the supposition that in the case where the iodide was decomposed, the phosphorus did not expose sufticient surface to absorb all the oxygen, and a mixture of phosphoric acid and oxygen went over, which by their simultaneous action on the potassium iodide set iodine free. But as soon as sufficient surface was given to the phosphorus all oxygen was absorbed, phosphoric acid alone was carried over, and the mixture of iodide and starch was not affected.

Concerning these results it is to be remarked:-

1st. Air ozonised by phosphorns, contains so small a percentage of ozone, that it must be passed through water at ordinary temperatures for a long time, to communicate to it the property of decomposing potassium iodide. If the wash-water is surrounded by ice, it acquires this virtue in a much shorter period (several hours). The decomposition is due in part to the hydrogen peroxide, which is likewise present. It is not owing to phosphorus or phosphoric acid, since these bodies do not directly decompose potassium iodide, nor to oxides of nitrogen, since the only one present is nitric acid.

$2 \mathrm{~d}$. Since electrolytic ozone was soluble in water, while that produced by the action of phosphorus on atmospheric air was not, Williamson thought he was dealing with two different substances.

* Repeated experiments, made since this time, have abundhntly justified the necessity of this precaution. And inasmuch as water was apparently formed by reduction, the ozoniferous gas produced by electrolysis was regarded as a peroxide of hydrogen. This again was held to be different from Thenard's peroxide, since the latter is not odorous, nor, as stated by Williamson, volatile. 
Schoenbein immediately assailed Williamson's results, ${ }^{*}$ and reiterated his oft-repeated declaration that the matter of the ozone produced in both cases was identical, an assertion abundantly verified by many subsequent experimenters.

$3 d$. Schoenbein also pointed out that in the final experiment with phosphorus, whicb Williamson regarded as conclusive, the finely divided phosphorus would destrov, by combining with it, the ozone as rapidly as formed.

SorET, in a paper entitled "Experiments on Ozone," $†$ states that he obtained by electrolysis, oxygen containing in 105 parts, 2 parts of ozone. But when the gas was collected under water, and absorbed with potassium iodide after all the gas had been disengaged, less oxygen was found, because water dissolves a considerable proportion (about one-fifth of the ozone liberated in an experiment in which the water was analyzed).

Merssxer, by prolonged contact of ozoniferous air, which had been ozonised by phosphorus and then agitated with water, with a little water obtained a liquid which exhibited the chemical reactions of ozone.f Hoczeac likewise found that water which had been in contact with ozone, manifested the ozone reactions. \&

Marigsac, in the 12th section of the memoir, $\|$ in which he overthrew the second hypothesis of Schoenbein, that nitrogen was a compound body of which ozone was one of the elementary constituents, stated that ozone undergoes no absorption nor alteration by voater, concentrated sulphuric acid, calcium chloride, ammonia or barytawater.

ANDREws states that ozone, from whatever source prepared, " is not absorbed by water, but when sufficiently diluted with other gases, is destroyed by agitation with a large quantity of water ; it is also contrary to the common statements, destroyed by being ayitated with lime-water and baryta-water, provided a sufficient quantity of these solutions be used."

Caril's, last of all, re-investigated the question with great pains and multiplied experiments.** His method was as follows: the ozonised oxygen employed was prepared by the electrolysis of cold

* Phil. Mag., xxvii, p. 451.

† Phil. Mag., xxv (1863), p. 209.

$\ddagger$ Untersuch. ueber d. Sauerst., Hanover, 1863.

Berichte der deutsch. chem. Gesell., vi, p. $60 \%$.

॥Compt. Rend. (1845), p. 808.

Ti Proc. Royal Soc., vii (18ñ6), p. 476.

** Berichte der deutsch. chem. Gesell., vi, p. 520 . 
diluted sulphuric acid, with platinum iridium electrodes, after the plan of Soret.* It was passed for about two hours into water, kept at a temperature of $+0.5^{\circ}$ to $3^{\circ}$. The proofs of the fact of absorption baving occurred, were, according to Carius :

I.-The strong and characteristic odor.

II.-The blueing of iodide-potassium-starch solution, and its subsequent bleaching by further addition of the ozone-water.

III.-Oxidation of thallous to thallic oxide.

IV.-Bleaching of indigo and litmus, and blueing of guaiacum tincture.

V.-The gas evolved from the solution and collected, showed the above reactions, and also acted upon manganese and lead papers, with formation of peroxide.

VI.-When fresh, bleached litmus paper, after several days, did not alter them (absence of nitrous acid).

VII.-It did not develope a blue color with acid potassium chromate and ether. After warming to $30^{\circ}$ and $40^{\circ}$ from $\frac{1}{2}$ to 1 hour, it no longer turned iodide-potassium-starch blue, even after addition of ferrous sulphate (absence of hydrogen peroxide).

Carius likewise determined by means of potassium iodide solution, the coefficient of solubility of ozone at various temperatures. For temperatures between $0.5^{\circ}$ and $3.2^{\circ}$, the anount of ozone absorbed in a liter of water was (mean of 3 trials) $9.4 \mathrm{mgrms}$, or $4.4 \mathrm{cc}$ at $0^{\circ}$ and $760 \mathrm{~mm}$.

Unfortunately, Carius found that the commercial "ozone-water" of Krebs, Kroll \& Co. (Berlin), in which be had disproved the presence of nitrous and nitric acids and hydrogen peroxide, gave the same reactions as the solution of ozone, which he had prepared himself. Moreover, it contained according to Carius, $9.55 \mathrm{mgrm}$ or 4.45 cc ozone per liter. Shortly after, C. Rammelsberg $\nmid$ examined this commercial ozone-water, and found that every sample examined, afforded a precipitate with silver nitrate. In one instance, the precipitate corresponded to $16 \mathrm{mgrms}$ chlorine per liter. Carius replied $\ddagger$ to this, that the "commercial ozone-water" which he had employed, manifested only the very faintest opalescence with silver nitrate, and had not affected silver foil inmersed in it. In his earlier communication, he had stated with reference to the effect of ozone-water on silver, that the latter was not blackened in case it were entirely im.

*Compt. Rend., lvi, 390.

+ Berichte der deutsch. chem. Gesell., vi, p. 603.

$\ddagger$ ib., vi, p. 809 . 
mersed in the water, but if not, and a little space was left in the flask above the water, a very perceptible blackening occurred. In one such successful trial, the commercial "ozone-water" was used, in another, that prepared by himself. In two other similar trials, with the latter, no blackening occurred.

In other words, the proof of the solubility of ozone adduced by Carius, breaks down at the most important point ; that is, whether or no such water has the power of forming silver peroxide upon silver which has been immersed in it. For not only is the silver test free from the objections, which might possibly be urged against the validity of the other tests, but if successful, would show that the ozone after absorption, retains a characteristic which is perhaps the one most illustrative of its energetic oxidizing power-that of being able to convert silver into the state of peroxide. It was determined, therefore, in attacking the problem again, to use more severe tests than those hitherto employed, and that among these the oxidation of silver, while completely immersed in water, should play a conspicuous part. Moreover, it was desirable to have a slow stream of the ozonised gas passing over, rather than through the water. As a convenient method of realizing these conditions, three of the phosphorus ozonators were placed in connection with one another.

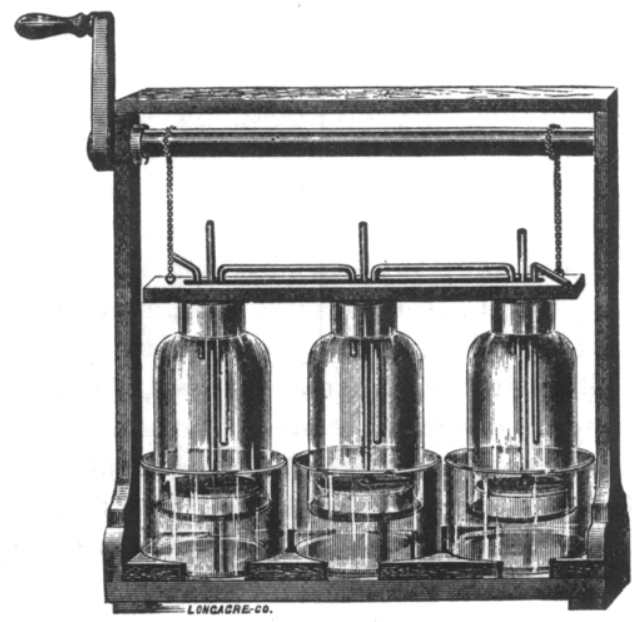

Fig. 1, Phosphorus Ozonator.

(First Form.)

Since these ozonators have been considerably modified, subsequent to the description originally published (Jour. Am. Chem. Soc., Vol. I, p. 10), we have introduced besides Fig. 1, representing the old form, a new wood-cut, Fig. 2, showing various improvements. These are briefly :

1. A washing tube, 25 $\mathrm{cm}$ long and $3 \mathrm{~cm}$ diameter, plugged with damp cotton-wool, and fastened along the cross-bar of the

apparatus, so as to intervene between the exit tube and kerite tubing, and filter out oxides of phosphorus, etc. In most cases it is greatly to 
be preferred to a wash bottle. A similar washing tube, plugged with amianthus moistened with alkali, is in like manner attached to the inlet tube when it is desired to purify from carbonic acid the air employed.

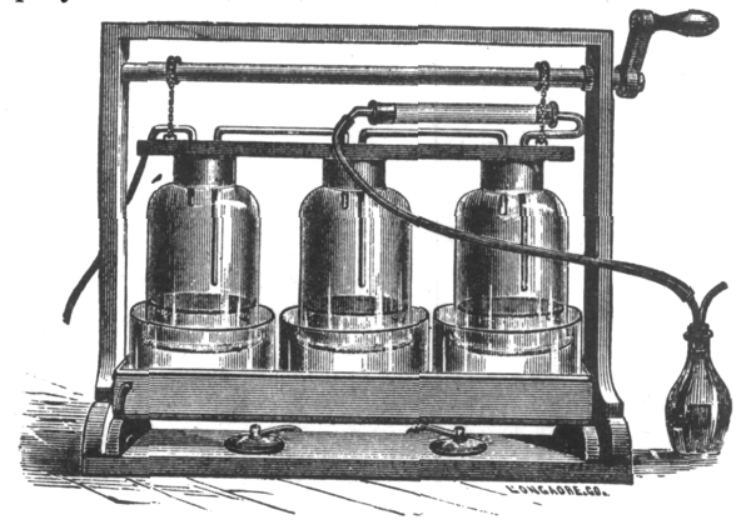

Fig. 2, Phosphorus Ozonator.

(Latest Form.)
2. The movable rods and stages are done away with, and the phos phorus eakes are supported on leaden dises, which rest on leaden brackets let into holes bored $\mathrm{thr}$ ough the bells a little way above their lower rims.

3. The jars rest upon crosspieces at the bottom of a long copper water bath, beneath which lamps are placed so as to retain the temperature at the point of maximum evolution of ozone $\left(24^{\circ}\right)$. These tanks are also provided with inlet and exit pipes so as to permit of the jars being cooled by a current of water, if desirable.

First experiment.-This experiment was instituted to determine (a) whether a difference existed in the rate of oxidation of lead plates, when immersed in aerated and in ozonised water, $(b)$ whether lead sulphide was ozonised to sulphate, and $(c)$ whether silver was peroxidized under like circumstances. The inlet tube of the first ozonator was connected with a soda-lime V-tube, to remove the carbonic acid. The weight of the lead disc ordinarily used to support the phosphorus cakes, was determined before beginning of experiment. The jar in which it was immersed contained distilled water. The exit tube of the first ozonator was connected with the inlet tube of the second, which was arranged with phosphorus in the ordinary manner, and used to generate the ozone. In order to remove the oxides of phosphorus, ammonium nitrate and hydrogen peroxide from the ozonised air, it was connected by means of kerite tubing with a long glass tube stuffed with damp cotton-wool, which effects this washing more thoroughly than an ordinary wash bottle. This cotton purifier was again connected by kerite tubing with a third ozonator. In this, 
the first bell contained a sheet of silver plate partly immersed in the distilled water of the jar; the second bell. a leaden disc painted over with white lead and previously blackened by exposure to hydrogen sulphide: the third bell, simply a weighed leaden disc. Both these discs were supported as usual, and were parallel to the surfaces of the distilled water in the second and third jars, at a depth of about $1 \mathrm{~cm}$.

Air was continuously aspirated through the apparatus for $7 \frac{1}{2}$ days, about 1800 liters containing 2.5 grms ozone being drawn over.

(a.) At the end of this period, dense white presipitates had formed in both jars containing the lead plates. These precipitates were crys. talline in character, presenting octahedral planes, and consisted of hydrated protoxide of lead. The lead plate in the bell throngh which air was drawn weighed $265.5 \mathrm{grms}$; the amount of hydrated oxide of lead produced, weighed after drying $0.4671 \mathrm{grm}$. The lead plate in the bell through which ozonised air was drawn, weighed originally 375.75 grms; the hydrated oxide of lead produced, 0.8802 grm or nearly twice that in the case of the water which had been in contact with air only.

(b.) The sulphide of lead was completely bleached.

(c.) The silver plate was blackened above the surface of the liquid, where it was in direct contact with the ozonised air, but not below.

Second experiment.-It was highly probable, therefore, that the ozone had gone into olution, since otherwise the increased production of hydrated lead oxide and the bleaching of lead sulphide, could lardly be accounted for. But inasmuch as negative results had been obtained in what might fairly be regarded as the crucial test-blackening of the silver plate-the experiment was repeated, though in a somewhat different manner. One of the phosphoris ozonators was attached to the kerite delivery tube of an electrical ozoniser. In one of the bells, a flat dish containing freshly precipitated and carefully washed lead sulphide was suspended, so that the lead sulphide should be immersed $1 \mathrm{~cm}$ below the surface of the water. In the second bell, a sheet of silver foil was placed, the lower half immersed in a slanting direction. A slow current of ozonised air, containing 24 mgrms of ozone per liter, was passed through the ozonator for 3 hours. The lead sulphide was not noticeably affected; the silver plate above the liquid was black and deeply corroded. Below the surface a number of flakes of oxide were found, which on removal left stain. upon the silver that could' not be washed or rubber off. 
Third experiment.-This was undertaken because we had not succeeded above in bringing about the oxidation of lead sulphide and silver at one and the same time. 5 filter papers of $12 \mathrm{~cm}$ diameter were saturated with lead acetate, blackened with hydrogen sulphide and dried. They were then fastened to one another and to the bottom of a flat crystallizing dish, with a few drops of paraffine, and sufficient water poured into the dish to cover the paper to the depth of about $1 \mathrm{~cm}$. The dish was then supported on the leaden brackets of the bell, so that it might be gently lowered into the water of the jar, without disturbing anything. A silver plate $15 \mathrm{~cm}$ in diameter was similarly arianged in the second bell. It had been polished with gypsum and alcohol, rinsed with caustic potash, then with alcohol, and finally completely immersed to the depth of $1 \mathrm{~cm}$ without bandling. 30 liters of ozonised oxygen, containing in all $0.72 \mathrm{grm}$ ozone, were passed in a frequently intermitted current into the apparatus, during an interval of 48 hours. Shortly after the operation began, a film appeared on the surface of the dish containing the lead papers, and increased until at the close it had become a pellicle with high lustre and of dark brown color. Under the microscope, no traces of crystalline structure were apparent, but the scales exhibited a beautiful dark red translucency. They dissolved in hydrochloric acid with evolution of chlorine, and proved to be anhydrous peroxide of lead.*

The liquid was strongly acid to litmus paper, and gave a precipitate with barium chloride, showing the presence of a notable amount of free sulphuric acid. In other words, the lead sulphide, under these circumstances, had become oxidized, not to lead sulphide as was anticipated, but into free sulphuric acid and anhydrous peroxide of lead.

The silver was not perceptibly affected until towards the end of 24 hours, when faint stains began to appear and increased until, at the end of 48 hours, they corresponded to about $\frac{1}{20}$ th the area of the plate. These films floated up to the surface, and had a dark grey color. On washing and drying the plate, its surface formerly like a mirror, was found to be similarly corroded.

Conclusion.-These results, it appears to us, are conclusive as to the much disputed point, whether or no ozone is soluble in water. Moreover, the oxidations effected appear to show that it retains even in solution, its maximum of oxidizing power. The fact of the solu-

* Dr. G. E. Moore, who repeated the microscopic examination with the use of much higher magnifying powers than I had employed, was likewise unsuccessful in finding any indications of crystalline structure. Moreover, according to Dr. Moore's observations. the scales do not annear to be doublv refracting. 
bility having been establisheri, there would seem to be no objection to adopting the approximate coetholents of solubility at various ternperatures, as determined by carius.

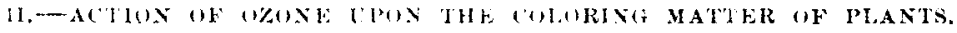

In the Annals of $X . I^{*}$. Acarlemy of Reiences, Vol. i, No. 7,1 . 216 , I have griven the results obtained when ozonised oxygen was made te act upon flowers and plants. They were cxposed to the action of a slow contimums current of ozonised oxygen containing 1 mgrm ozone per liter, during intervals valying from 18 to 30 hours. The results, which vere manly negative, wereso matisfactory, that I have repeated them with the aill of more eftiocions apparatus for generating ozone.

One phosphorus ozonator was employed to supply ozone, another, without the phosphorus akes upon the lises, made a convenient arrangement to contain the flowers. As their stems were placed in vessels filled with water, and the bells were closed by the water contained in the jars, the atmosphere surrounding the flowers was kept moist, which was of importance in the conduct of the experiment.

1. Bleaching of Flowkrs (152 liters of air pased over).

\begin{tabular}{|c|c|c|}
\hline & After 10 houry (120 ing Ims ozunel. & After 10 hourd (228 mgrms) \\
\hline Ieliotrope, & Dirty yellow. & Bleached, leaves also. \\
\hline & es bleached at ends.) & All perfume destroyed. \\
\hline a, & Yellow at end of petals. & $\begin{array}{l}\text { Partly bleached. } \\
\text { Leaves white in spots. }\end{array}$ \\
\hline & White in spots & Some petals white. \\
\hline & Little affected. & Jittle affected. \\
\hline$y(p u r p l e)$ & White in spots. & More bleached. \\
\hline
\end{tabular}

At the end, therefore, of 19 hours, when 152 liters of air containing in all $228 \mathrm{mgrms}$ of ozone had passed over, the bleaching was very imperfect.

2. 1200 LITERs of AIR PAsínd OVER (total ozone 1.8 gl'ms).

Lintana, red, Fuchsia, calyx, carnation-red, petals, rose-pink,

Petunia, magenta-colored,

Rose, crimson,

Agapanthus umbellatus,

Verbena, purple with wh. centre,

Pelargonium, scarlet,

Euphorbia, salmon-colored,

Fuchsia,

Verbena, maroon-colored, t the end of 5 days.

Yel'w and somewhat decomposed. Yellow.

Dirty white.

Calyx and petals partly bleached.

Yellow.

White at end of petals.

Bleached. “

Partly bleached.

Calyx and stamens yellow.

Dirty white. 
A piece of calico with a pattern in black and bright green was completely bleached during the same interval, the green color having disappeared completely, and the stain of the mordant only remaining where the black had been.

\section{Ozoniski Oxygen (exposed for $3 \frac{1}{2}$ hours).}

Rose, light red,

Fuchsia,

Verbena, purple,

" red,

Petunia, purplish-red,

Pelargonium, pink,

Bouvardia,
Nearly white, leaves white in spots. Bleached to light red.

White with purple spots.

White with red spots.

White in spots.

White at end of petals.

Dirty white.

No determination was made of the percentage of ozone during this particular experiment. But the same ozoniser was employed as in other trials, when it had produced 24 mgrm ozone per liter. A slow current of the gas was kept flowing during the course of the entire experiment.

Conclusion.-The coloring matters of both leaves and flowers of the species experimented upan, were destroyed by ozone. But a considerable percentage of ozone is required to produce this result, or if such small amounts as are obtained in the customary methods of ozonising air by phosphorus are employed ( 1 to $3 \mathrm{mgrms}$ per liter), a large volume of ozonised air must be used, and a considerable interval elapse, before bleaching is effected.

\section{III. - BIFACHING (IY SUGAR SYRUPS BY OZONE.}

Not being able to find in chemical journals, any accounts of experiments made upon colored syrups with ozone as a bleaching agent, while there were rumors that such experiments had been tried, although with very partial success, it appeared the easiest way of obtaining satisfactory knowledge upon this point, to make suitable trials in this laboratory. 'The material was kindly furnished by $\mathrm{Dr}$. Arno Behr, from syrups manufactured in the refinery of Messrs. Matthiessen \& Wiechers, Jersey City. The first specimen, was of syrup which had undergone but one filtration, and was of a brownishyellow color. In this preliminary experiment, the amount of ozone required to effect the bleaching was not determined. At its close, the syrup was of a faint straw-color and of slightly acid reaction.

A second trial was made upon a syrup which had been twice filtered, still retaining a strong yellow tint. $20 \mathrm{cc}$ of the syrup were 
introduced into a Geissler absorption apparatus, and a slow current of oxygen, ozonised to the extent of $24 \mathrm{mgrm}$ ozone per liter, was passed through it for several hours. When about 100 mgrm ozone had been brought into contact with the syrup, it had become almost tolorless. To our litmus paper it was neutral, although Dr. Behr informs me he detected a very faint acid reaction.

As determined by Dr. Behr, the tiltered syrup when it came from the refinery, contained in 100 parts, 50 parts of dry substances and 40 parts of pure sugar. The alteration in bleaching, is seen in the following table.

Effect of Ozone tipon Filtered Syrup.

Dry substance contains

Cane sugar (by polariscope) - - $\quad 79.7$ per cent.

Inverted sugar

12.7

Bleached.

o0.0 per cent.

$12.7 \quad 66$

IV.-REDCCTION OF CARBONIC ACID BY PHOSPHORLS AT ORDINARY TEMPERATURES.

As a preliminary determination, rendered essential in the progress of certain studies, it became necessary to ascertain whether phosphorus was entirely without action upon carbonic acid at ordinary temperatures. The inquiry was set on fout with the expectation merely of arriving at a negative result. The experiment was conducted as follows: the three leaden dises of the phosphorus ozonator were covered with cakes of fresh phosphorus, and lowered beneath the surface of the water in the jars. After the air had been completely expelled by a very long continued current of carbonic acid, the cakes were raised so as to bring them in contact with the gas. As it issued, the gas flowed through a potassium iodide wash bottle, and then through a Peligot tube, containing strips of paper saturated with solution of palladium chloride. After 5 hours, the iodide was unaffected, but the palladium papers were blackened, and the liquid at the bottom of the $V$-tube contained a notable precipitate. On replacing the papers by fresh ones, they were blackened in the conrse of 15 minutes. Allowed to remain over night (16 hours), and aspirated with proper precautions through solution of palladium chloride, the latter showed an increase in weight of $40 \mathrm{mgrms}$.

Two wide-mouthed flasks were tilled with carbonic arid, great precautions being taken to exclude air. Each contained several sticks of phosphorus, partly covered with water. After sealing, one was placed in the dark, the other in sunlight, and both allowed to remain 
for 24 hours. As in the preceding experiments, dense fumes arose in both bottles, those in the bottle exposed to sunlight being attended with the deposit of much sublimed yellowish-red phosphorus. On testing the contents, both flasks gave straightway the carbonic oxide reaction.

Finally, a quantitative determination of the amount of carbonic oxide produced, was made in the following manner : a 5 liter jar was entirely filled with water, the air in the generating apparatus and the various wash bottles, etc., was removed by a long continued current of carbonic acid, and at last the jar was filled with the gas, the last traces of oxygen having been taken out by the interposition of a wash bottle containing potassium pyrogallate. After standing for 4 days in contact with the phosphorus and water at bottom of the jar, the residual gas was drawn off ; first, through a long moist cotton filter, then through a potassium iodide solution, then through 3 V-tubes, filled respectively with $\mathrm{CaCl}_{2}, \mathrm{Cu}_{2} \mathrm{Cl}_{2}$ and $\mathrm{CaCl}_{2}$, the last acting as a guard. The iodide solution underwent no change, but the acid solution of cuprous chloride had absorbed 0.150 grm of carbonic oxide.

Formation of phosphuretted hydrogen in the course of this reduction.-Of scarcely less interest and novelty, was the generation of hydrogen phosphide during the reduction of carbonic acid. This fact was at once made strikingly apparent on opening the flask above mentioned, and which had been exposed to the sun, by the very powerful and characteristic sinell. On plunging a strip of paper wet with silver nitrate into the gas, a dense precipitate of silver was formed immediately. This reduction of the silver salt did not occur on immersing similar strips in an atınosphere of carbonic oxide. The reaction which occurs in these cases is not improbably correctly represented in the equation :

$$
6 \mathrm{P}+5 \mathrm{CO}_{2}+3 \mathrm{H}_{2} \mathrm{O}=\mathrm{P}_{2} \mathrm{O}_{5}+\mathrm{P}_{2} \mathrm{O}_{3}+2 \mathrm{PH}_{3}+5 \mathrm{CO} \text {. }
$$

Mutual reactions of water and phosphores. - The foregoing results raised the question whether the hydrogen of water might not deport itself, at common or somewhat elevated temperatures, towards phosphorus as a basic radical and, in this case, the water undergo decomposition according to the equation :

$$
\mathrm{P}_{4}+6 \mathrm{H}_{2} \mathrm{O}=2 \mathrm{H}_{3} \mathrm{PO}_{3}+2 \mathrm{PH}_{3} \text {. }
$$

To answer this question, water which had been boiled for a number of hours in order to expel the air, was digested for 48 hours, at a temperature of $92^{\circ}-96^{\circ}$ with phosphorus, and the minute amount of gas, given off, collected and examined. Not a trace of bydrogen phosphide was found, thus negativing the above hypothesis. 


\section{OXIDATION OF CARBOYIC OXIDE BY AIR OVER PHOSPHORUS AT ORDNARY TEMPERATTRES.}

Having demonstrated, by some preliminary experiments, that carbonic oxide was converted into acid by air over moist phosphorus at common temperatures, the following experiment was made, in order to determine the amount of carbonic acid formed. A 5 liter jar containing 5 sticks of phosphorus and a little water, was filled with 2500 cc of carbonic oxide and the remaining space with air. The carbonic oxide was made from potassium ferrocyanide and sulphuric acid, and washed with water, caustic potash and baryta water. On transferring it to the jar, it was washed again in similar manner, a tinal $V$-tube filled with baryta water remaining pellucid, showing the absence of any carbonic acid. The air was purified likewise. At the expiration of 18 hours, the gases were drawn first through a moist cotton filter, then through a potassium iodide solution, and finally through two baryta waters. The faint rose coloration which the iodide solution struck with starch water, corresponded to $0.04 \mathrm{mgrms}$ ozone in the total volume of gas drawn over; the last baryta water remained clear, the first had absorbed 14 mgrms carbonic acid. The carbonic acid estimation was made by decomposing the barium salt, and weighing the carbonic acid gas evolved, for fear that some traces of oxide's of phosphorus might have escaped the purifiers, and entered into combination with the baryta.

Experiments instituted in order to determine whether pure carbonic oxide, subjected to the action of muist phosphorus, for long periods and in some cases with the conjoint action of sunlight, would result in the reduction of the carbon compound to some lower oxide or to the elementary condition, gave a negative result. 